\title{
Acessibilidade e infraestrutura urbana no Campus Central da UFRN: opinião de pessoas com deficiência e idosos
}

\author{
Accessibility and urban infrastructure at the UFRN Central Campus: \\ opinion of people with disabilities and the elderly
}

NATALYA CRISTINA DE LIMA SOUZA

Arquiteta-Urbanista, Mestranda do PPGAU-UFRN, natalyalimasouza@gmail.com

\section{RESUMO}

Este artigo apresenta alguns resultados de uma pesquisa que captou as opiniões de Pessoas com Deficiência (auditiva, cognitiva, física e visual) e idosos sobre os espaços de infraestrutura urbana no Campus Central da Universidade Federal do Rio Grande do Norte. O objetivo é compreender a percepção desse grupo diante das recentes políticas de inclusão e ações de acessibilidade. A metodologia do estudo foi baseada na avaliação do banco de dados de pesquisa realizado em 2016, que envolveu análise de documentos, produção de mapas e aplicação de questionário aos usuários do Campus. Apesar do crescimento de projetos relacionados à acessibilidade física, principalmente de sinalização e nivelamento de quinze rotas acessíveis, os resultados mostraram percepções negativas. Entre os aspectos que caracterizaram a inadequação da infraestrutura estão: (1) problemas de estacionamento, com consequências diretas nas calçadas e acesso aos edifícios; (2) falta de sinalização diversificada, causando dificuldades na orientação e legibilidade; (3) má qualidade da linha de ônibus interna; e (4) barreiras atitudinais. Três anos após a pesquisa, é possível afirmar que ainda existem algumas dificuldades, principalmente no acesso a prédios e pontos de ônibus fora das rotas acessíveis. Mas as contribuições do diagnóstico podem substanciar novos projetos de intervenção para a garantia da maior usabilidade dos espaços e acessibilidade integral.

PALAVRAS-CHAVE: acessibilidade física, infraestrutura urbana, percepção, campus universitário

\begin{abstract}
This paper presents some results of a research which captured the opinions of Persons with Disabilities (hearing, cognitive, physical and visual) and the elderly about the urban infrastructure spaces at the Central Campus of the Federal University of Rio Grande do Norte. It aims to understand the perception of this group in the face of recent inclusion policies and accessibility actions. The study methodology was based on evaluation of the research database held in 2016, which involved document analysis, map production and application of questionnaire to Campus users. Despite the growth in projects related to physical accessibility, mainly the signaling and leveling of fifteen accessible routes, the results showed negative perceptions. Among the aspects that characterized the inadequacy of the infrastructure are: (1) parking problems, with direct consequences on sidewalks and access to buildings; (2) lack of diversified signage, causing difficulties in orientation and legibility; (3) poor quality of the
\end{abstract}




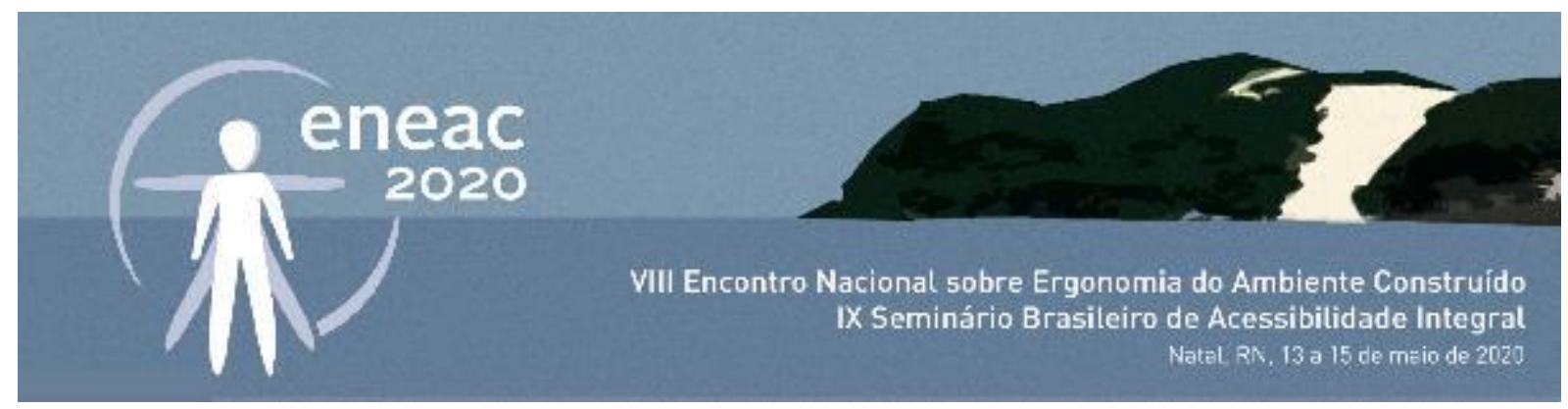

internal bus line; and (4) attitudinal barriers. In three years after the survey, it is possible to state that some difficulties still persist, especially in accessing buildings and bus stops outside accessible routes. But the contributions of the diagnosis can substantiate new intervention projects for guarantee greater usability of the spaces and full accessibility.

KEYWORDS: physical accessibility, urban infrastructure, perception, university campus

\section{INTRODUÇÃO}

O ambiente universitário público, como reflexo da sociedade, recebe cotidianamente usuários diversos, em termos de idade, status social, escolaridade e habilidades físicas/sensoriais/cognitivas. Seja como visitantes, profissionais ou estudantes, essas pessoas enriquecem a comunidade acadêmica, demandando por um ambiente que atenda às suas necessidades e atividades.

Dentre os elementos que proporcionam a qualidade de vida nesse ambiente, estão o conforto (térmico, acústico e ergonômico), segurança e estímulo às relações sociais. Além disso, quanto a qualidade urbanística e arquitetônica, está a garantia do desempenho funcional da instituição, através do bom estado de conservação das instalações e capacidade de compreensão e circulação dos espaços, com níveis de mobilidade e acessibilidade aceitáveis (RODRIGUES, 2007).

Sendo a acessibilidade um componente da qualidade ambiental, ela é compreendida como um conjunto de medidas que reduz a segregação das pessoas com deficiência ou mobilidade reduzida, aumentando a autonomia de uso dos espaços (ABNT 2015). A partir de uma perspectiva física, visando o espaço construído e seu entorno, sua responsabilidade se estende a não exclusão espacial, combatendo barreiras (físicas, informacionais, sociais e atitudinais) e garantindo condições para acesso, uso e permanência. Nesse sentido, a prática do desenho universal favorece esse comportamento integral, visto que é destinada a acolher todos os usuários em potencial, sem promoção de soluções específicas e sim, as que atendem a maior extensão possível de pessoas.

Diante dessas preocupações, durante o avanço dos anos 2000, diversos marcos legais foram regulamentados para esclarecer sobre o tema e orientar as ações institucionais (ABNT 2004; 2015; BRASIL, 2015). No âmbito universitário, houve a sanção da lei no 13.409/2016 (BRASIL, 2016), que incluiu a reserva de vagas com cotas para Pessoas com Deficiência (PCDs) e da portaria no 20 do Ministério da Educação (BRASIL, 2017), que prevê, dentre as medidas para reconhecimento e renovação de cursos, a existência de um plano de garantia de acessibilidade.

Como algumas dessas legislações foram aprovadas e publicadas recentemente, elas enfatizam a necessidade de analisar as condições de infraestrutura dos campi brasileiros, especialmente dos que acomodam prédios antigos e novos. Além disso, é preciso discutir o impacto das mudanças provocadas pelo programa de Reestruturação e Expansão das Universidades Federais (REUNI) instituído pelo Decreto $n^{\circ} 6.096 / 2007$ (BRASIL, 2007) e implementado entre 2008 e 2012. Pois, como contou com uma adesão maciça das universidades, incentivou diversas ações de expansão, como ampliação de vagas, criação de novos cursos e reforma e construção de edificações e mobiliários urbanos, visando o acolhimento dos usuários.

A fim de analisar como as transformações na infraestrutura das universidades contribuíram para a melhoria das condições de acessibilidade espacial. E, não apenas desses estudantes, mas dos usuários que mais se sujeitam a transpor barreiras, o objetivo desse artigo é compreender a 


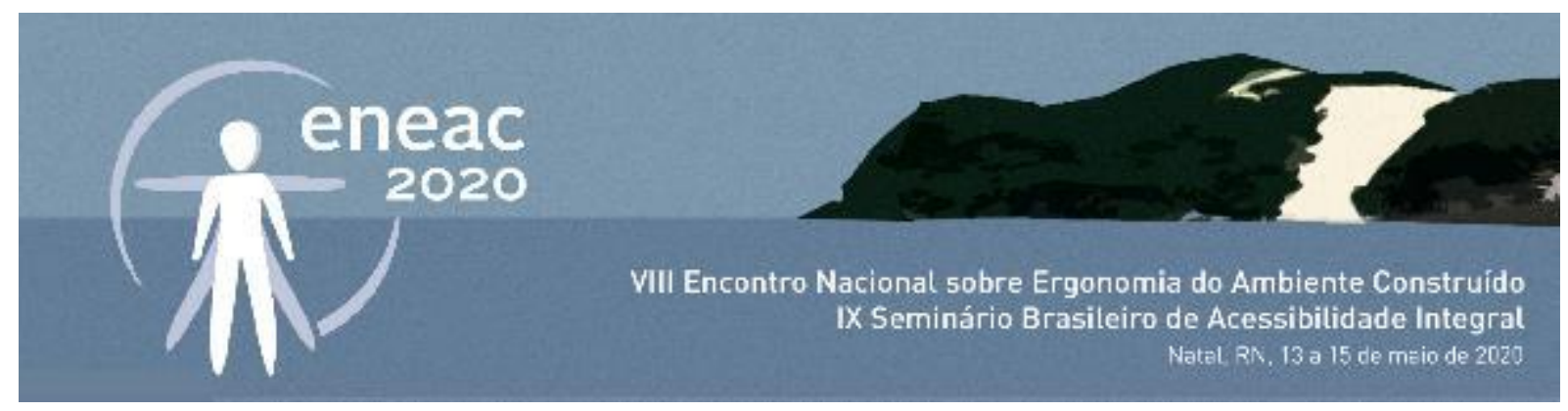

percepção das PCDs e idosos do Campus Central da Universidade Federal do Rio Grande do Norte (CC-UFRN), em termos de qualidade da mobilidade e infraestrutura dos espaços livres de apoio às edificações (circulações de veículos/pedestres e estacionamentos).

A metodologia do estudo partiu de avaliação do banco de dados da autora, sobre pesquisa realizada anteriormente no CC-UFRN (em 2016), que envolveu análise documental, produção de mapas e coleta de opinião dos usuários por meio de questionário. A descrição dos procedimentos será esclarecida no tópico seguinte (2), seguido de discussão sobre o universo de estudo e as ações de acessibilidade da instituição (3), com posterior apresentação das principais respostas desse grupo, analisadas a partir do questionário (4). As considerações finais contribuem para responder ao objetivo e levantar outras possibilidades de estudo do tema a serem exploradas.

\section{METODOLOGIA}

A iniciativa de direcionar a discussão desse artigo sobre a percepção das PCDs e idosos, partiu do banco de dados do levantamento realizado em uma pesquisa anterior sobre os espaços livres no Campus Central (CC) da UFRN (SOUZA, 2017). Esse trabalho aconteceu durante o ano de 2016 e se dividiu em duas etapas. A primeira consistiu em: observações e registros fotográficos de todos os espaços livres do campus; análise de documentações da instituição sobre histórico de construções e políticas de acessibilidade; e atualização de mapas fornecidos pela Superintendência da Infraestrutura (SIN). Essas informações estão organizadas no tópico 3 deste paper.

Na segunda etapa, um dos objetivos era investigar a opinião da comunidade acadêmica sobre as relações de uso, assimilação, qualidade e percepção dos Espaços Livres do CC-UFRN. Para isso, foi aplicado um questionário com 50 perguntas divididas em 6 seções ( $i$ - Dados pessoais; ii - Mobilidade campus-cidade; iii- Mobilidade interna e estacionamento; iv - Apoio; v - Ambiental; vi - Segurança). Ele foi elaborado na plataforma de formulário online do Google e encaminhado via e-mail para docentes, discentes e servidores do CC-UFRN através do Sistema Integrado de Gestão Acadêmica (SIGAA). Para respondê-lo, era necessário que cada um confirmasse a leitura do Termo de Consentimento Livre e Esclarecido (TCLE).

A coleta ocorreu durante o mês de novembro de 2016, e a análise das repostas foi feita a partir de tabelas dinâmicas e gráficos produzidos através do sistema do Excel. Devido a quantidade de questões, priorizou-se por perguntas fechadas (de múltipla escolha e escala) e algumas abertas curtas sobre aspectos percebidos no ambiente. Dentre elas, destacou-se na seção de mobilidade interna, a questão "A infraestrutura do Campus está adequada para receber pessoas com deficiência?". Dos 1210 respondentes, $58,43 \%$ respondeu que 'não' e $18,10 \%$, 'sim'. Sendo que $23,47 \%$ assinalou a opção 'não sei avaliar', percentual maior do que o de resposta positiva.

Os valores correspondentes a essa resposta estimularam a necessidade de estudar a opinião desse grupo específico, assim como dos idosos. Para isso, foram extraídas as respostas das três primeiras seções, com 30 questões ( $\mathrm{i}$ - Dados pessoais; ii - Mobilidade campus-cidade; iii- Mobilidade interna e estacionamento), dos usuários que indicaram ter alguma deficiência e também dos idosos (considerando acima de 59 anos), totalizando 4,21\% do quantitativo geral. A análise está discutida no tópico 4 deste artigo. 


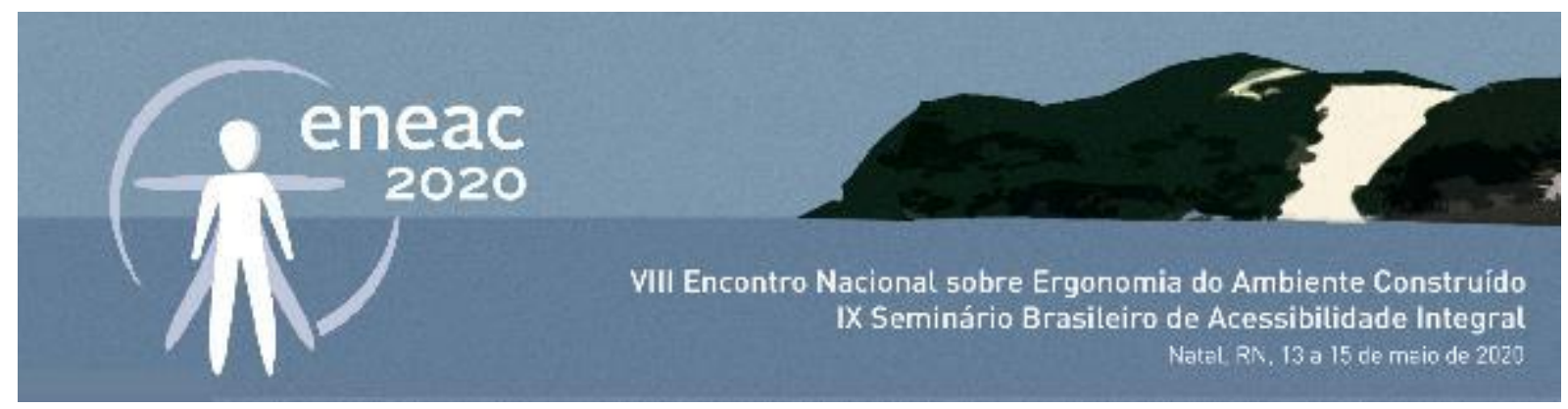

\section{O CAMPUS CENTRAL DA UNIVERSIDADE FEDERAL DO RIO GRANDE DO NORTE}

O Campus Central da Universidade Federal do Rio Grande do Norte (CC-UFRN) está localizado na porção sudeste da Cidade de Natal-RN (Figura 1). A sua origem se deu concomitante com a instalação de conjuntos habitacionais no seu entorno, loteados em meados dos anos 1960 e edificados a partir da virada da década de 1970 (PREFEITURA MUNICIPAL DO NATAL, 2008). Antes disso, alguns cursos já possuíam prédios em outros bairros. Na época, a reserva do terreno para o campus, nessa região da cidade, resultou da intenção de se resguardar a posição da universidade acomodada ao contexto urbano existente, e não nas áreas periféricas (ATCON, 1966).

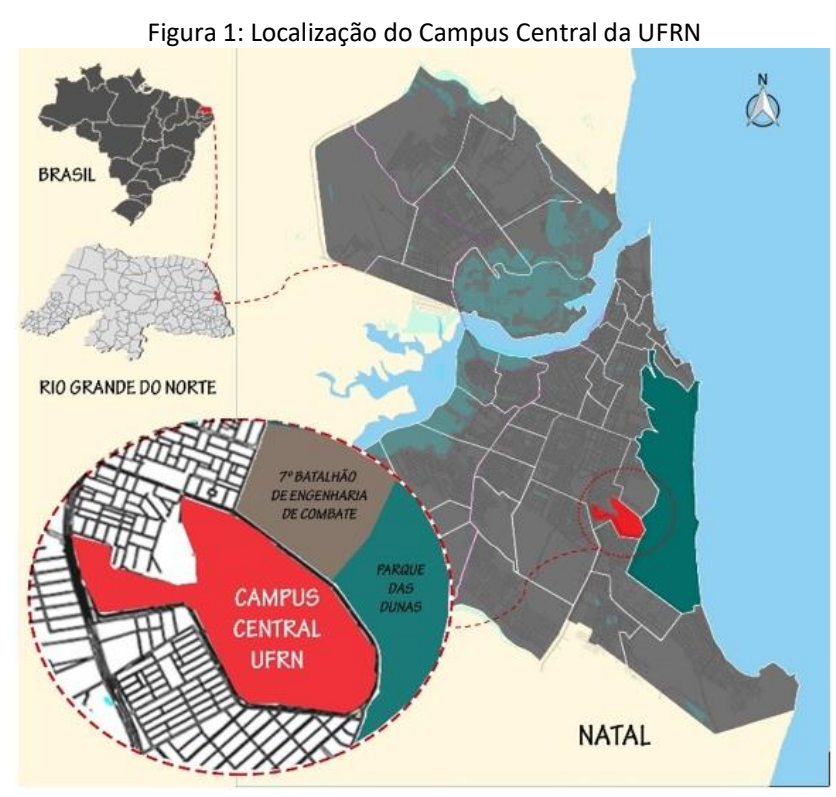

Fonte: Elaborado pela autora a partir de CONSAD, 2007.

Desse modo, com exceção da orientação leste, que é margeada pelo quartel do 70 Batalhão de Engenharia de Combate e o Parque das Dunas (Zona de Proteção Ambiental: ZPA-2), o CC-UFRFN está inserido em um bairro predominantemente residencial e se integra solidamente com o sistema viário da cidade. Em termos de edificações, a área do terreno de 123 ha, já tinha no fim da década de 1970, um pouco mais de $50 \%$ do percentual total de edificações existentes (até o fim de 2016), mantendo uma média de crescimento de $9,8 \%$ por período (Tabela 1 ). As construções até o fim da década de 1990 eram térreas ou de primeiro andar e continuam preservadas assim. A partir dos anos 2000, a tendência foi de se edificar prédios com três a quatro pavimentos, ocupando menos área do lote.

\begin{tabular}{c|c|c}
\multicolumn{3}{c}{ Tabela 1: Quantitativo da ocupação do Campus Central da UFRN } \\
Período & $\begin{array}{c}\text { Percentual de edificações sobre total } \\
\text { existente até fim de 2016 }\end{array}$ & $\begin{array}{c}\text { Percentual da ocupação } \\
\text { acumulada por período }\end{array}$ \\
\hline Meados da década de 1970 & $32,40 \%$ & $32,40 \%$ \\
\hline Fim da década de 1970 & $18,61 \%$ & $51,01 \%$ \\
\hline Fim da década de 1980 & $12,46 \%$ & $63,47 \%$ \\
\hline Fim da década de 1990 & $8,95 \%$ & $72,42 \%$ \\
\hline Fim de 2006 & $16,80 \%$ & $89,22 \%$ \\
\hline Fim de 2016 & $10,78 \%$ & $100,00 \%$ \\
\hline \multicolumn{3}{l}{}
\end{tabular}

Como sua configuração espacial se assemelha a maioria dos campi federais da Região Nordeste, com 


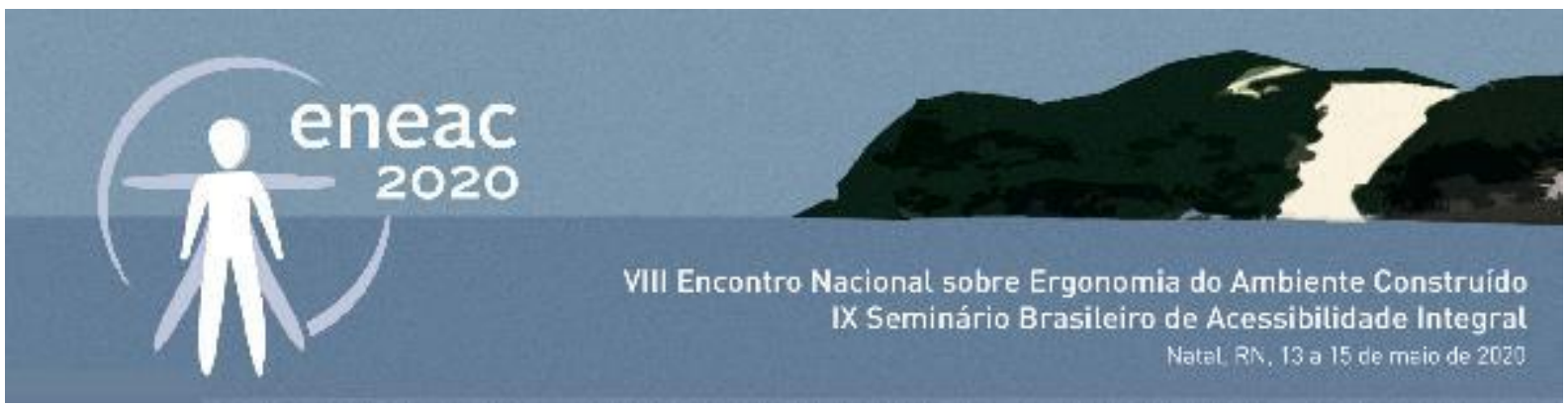

setorização das áreas de ensino e de administração/serviço zoneadas em um vasto território (OLIVEIRA, 2005), foi implementado um sistema viário hierarquizado, com distribuição dos estacionamentos e espaços públicos de lazer e convivência próximos as principais edificações (Figura 2). A via arterial corresponde ao anel viário e as distribuidoras, cruzam o CC. A diversidade de altitude topográfica, que vai de $35 \mathrm{~m}$ a $55 \mathrm{~m}$ (Figura 3), provocou algumas situações de desnível acentuado, que desfavorecem o deslocamento a pé e gerou a não ocupação de algumas áreas residuais.

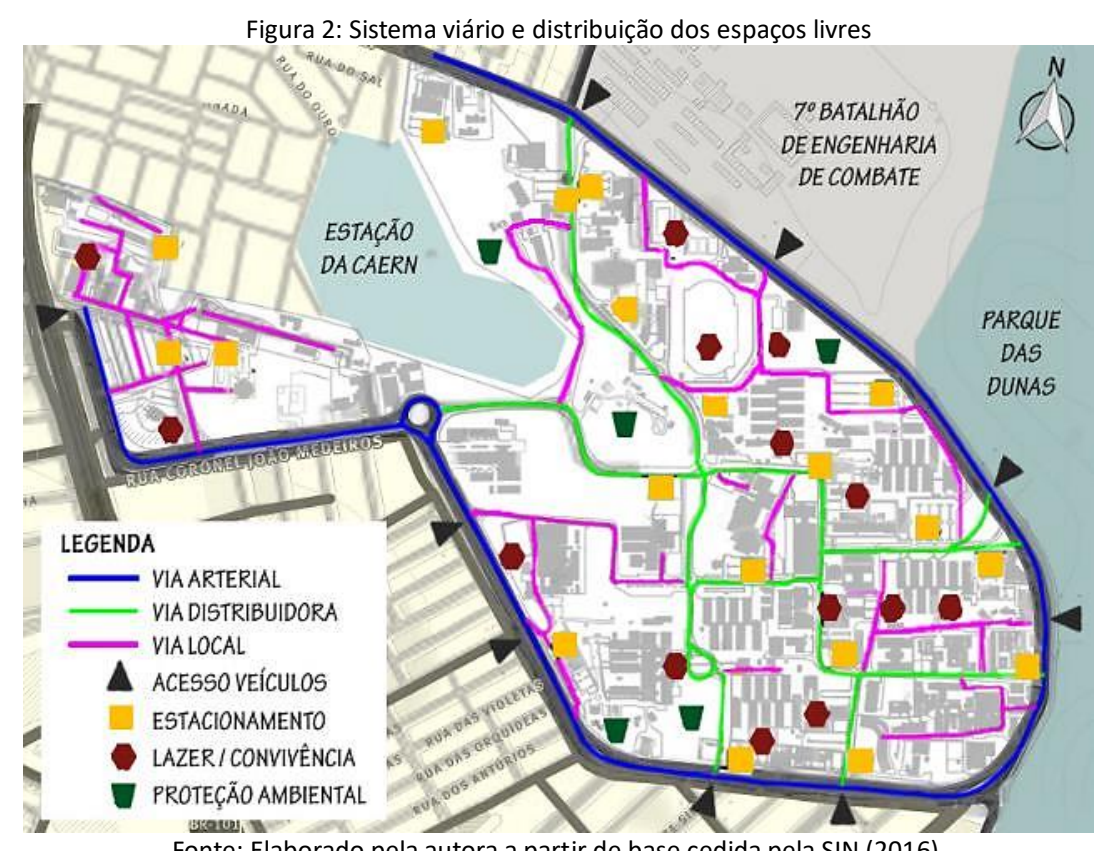

Fonte: Elaborado pela autora a partir de base cedida pela SIN (2016)

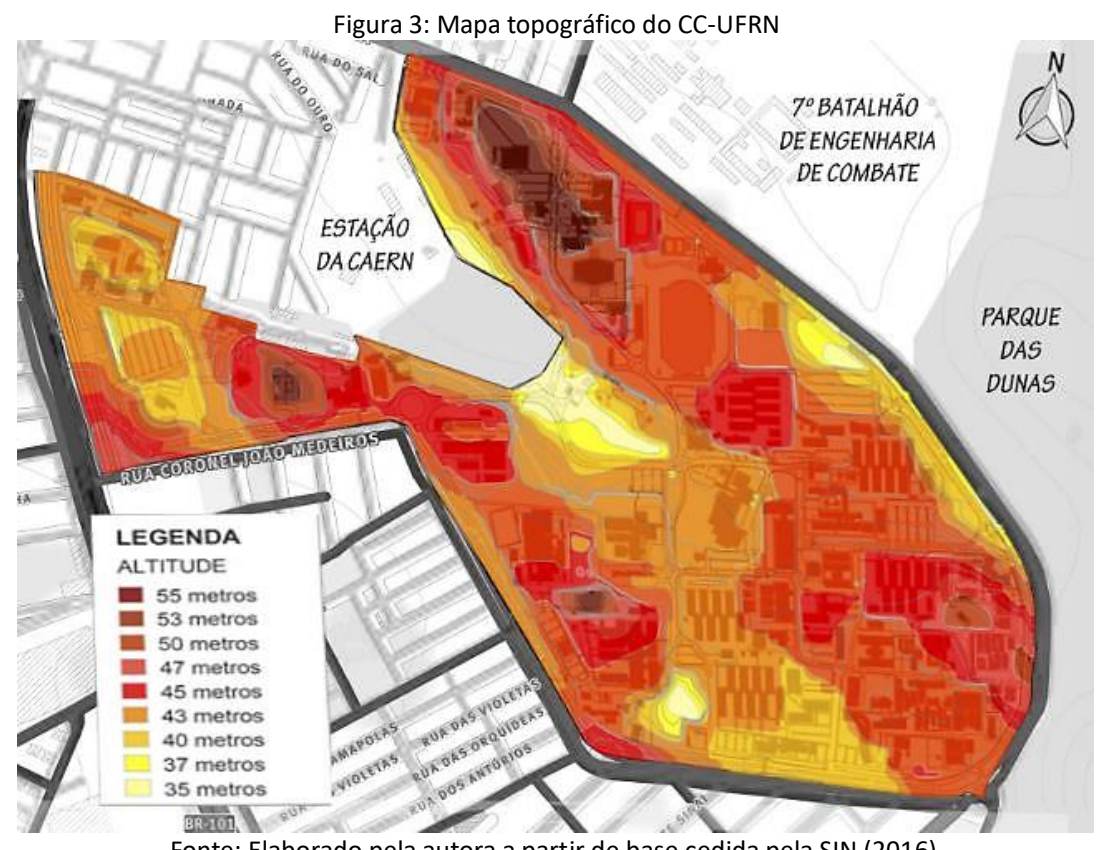

Fonte: Elaborado pela autora a partir de base cedida pela SIN (2016). 


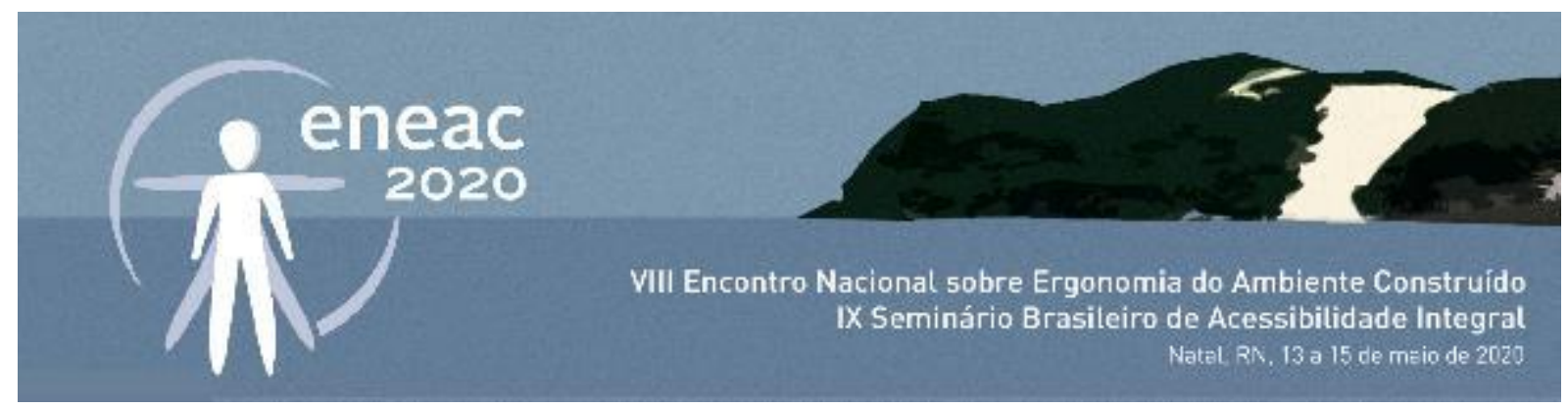

Em termos de modais de transporte, atualmente o CC-UFRN conta com 14 portões de acessos para pedestres a partir do anel viário, sendo 9 desses associados com entrada de veículos, reguladas por sistema de cancela. Ele ainda oferece, desde 2015 um sistema de ciclovia com cerca de $8 \mathrm{~km}$, além de 26 pontos de ônibus para linhas municipal, intermunicipal e a frota interna, o "Circular" (linha 588 Circular/Campus UFRN). Esse modelo local opera a partir de dois terminais principais, um dentro do campus, próximo ao Restaurante Universitário e outro externamente, no Shopping Via Direta, responsável por se integrar as demais linhas da cidade. Assim, a frota atual de 8 ônibus se divide em duas para cada operação: Expresso Reitoria, Expresso C\&T, Direto e Inverso (LIMA, 2017).

A presença dessa variedade de sistemas de circulação é passível de constantes análises quanto à qualidade e manutenção, especialmente embasadas por publicações locais (ELALI, 2004; GRILO, 2016; LIMA, 2017; SARMENTO, 2017). Sobre as questões de acessibilidade, a criação, em 2010, da Comissão de Apoio a Estudantes com Necessidades Educacionais Especiais (CAENE), além de avanços na política de acesso à informação e à comunicação, foi fundamental para diagnosticar e orientar ações ligadas ao aspecto físico, como demonstrado no seguinte subitem.

\section{Dados da acessibilidade física da UFRN}

Desde 2007, o Plano Diretor do CC-UFRN (CONSAD, 2007) previa a garantia das condições de circulação e acessibilidade universal no campus. As vistas de ir em concordância com a legislação da NBR 9050 vigente na época (ABNT, 2004), instituiu que era responsabilidade de uma Comissão de Gestão do Espaço Físico (liderada pela Superintendência da Infraestrutura), orientar sobre as intervenções no espaço, relacionadas à projetos arquitetônicos e de mobilidade urbana.

No entanto, somente um ano após a criação da CAENE é que a Superintendência da Infraestrutura (SIN) deu início a realização de um diagnóstico de acessibilidade em seus campi, vistoriando no central, 81 edificações e seus entornos imediato. Na época, a instituição já estava recebendo os recursos do Ministério da Educação (MEC), através do programa REUNI, e por meio desses investimentos, criou novos cursos e ampliou vagas, expandindo também fisicamente, com novos prédios que alteraram a configuração espacial e algumas circulações.

Em 2011, o relatório do CC-UFRN identificou 15 percursos realizados pela maioria dos usuários, que poderiam ser estruturados para se tornarem rotas acessíveis (Figura 4). Eles possuem extensões variadas, porque, além das mudanças dos níveis topográficos, são trajetos que contemplam os principais pontos de ônibus, centros acadêmicos, setores de aulas e edifícios de serviço e administração. Os resultados dessa publicação (UFRN-CAENE, 2011) incentivaram a elaboração de um manual (UFRN-CAENE, 2012), com orientações básicas sobre os principais aspectos a serem monitorados para a garantia de realização e adequação de projetos urbanos e arquitetônicos, dentre eles: ponto de ônibus, calçadas, estacionamentos, acessos, sanitários, portas, balcões e salas de aula. 

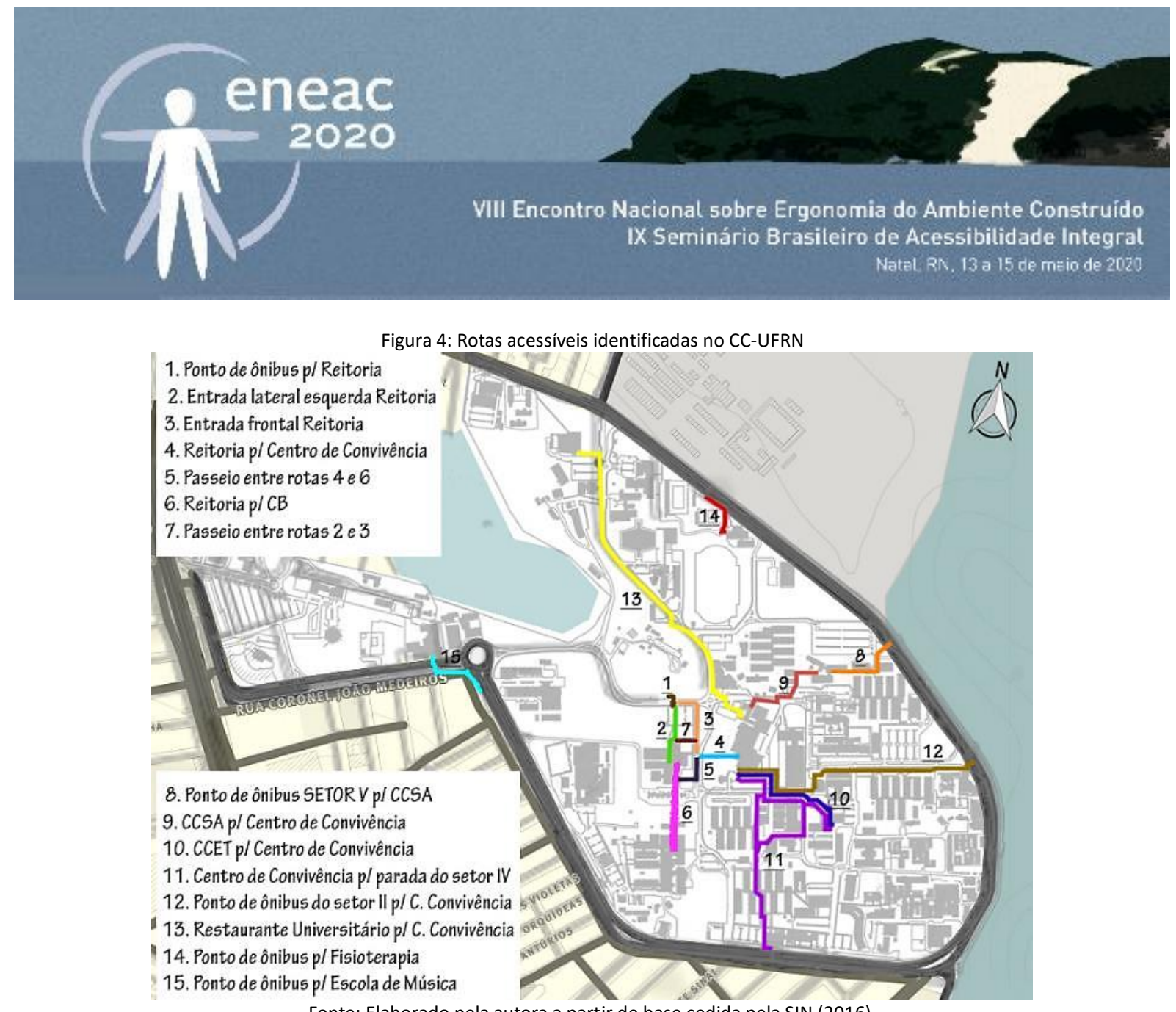

Fonte: Elaborado pela autora a partir de base cedida pela SIN (2016).

Após a publicação desse manual, as ações de acessibilidade física se intensificaram (SIN, 2019), a partir de 2014 (Tabela 2). É importante ressaltar que desde a primeira edição da NBR 9050 (ABNT, 1995), as obras da UFRN seguem as indicações da norma. Portanto, conforme ela foi atualizada (ABNT, 2004, 2015), algumas edificações demandavam reformas, seja em aspectos gerais ou em ambientes específicos, como banheiros e vestiários. Ainda sobre mudanças arquitetônicas, a instalação de plataformas de elevação verticais é uma demanda que vem crescido, especialmente porque os prédios atuais possuem mais andares.

\begin{tabular}{|c|c|c|c|c|c|}
\hline Títulos & 2014 & 2015 & 2016 & 2017 & $2018-2019$ \\
\hline $\begin{array}{l}\text { Reforma de edificações (Adequação à NBR } \\
9050-2004 / 2015)\end{array}$ & 02 & 01 & 03 & 03 & 01 \\
\hline Reforma de banheiros/vestiários & - & 01 & 01 & 01 & - \\
\hline Instalação de plataforma vertical & - & - & - & 04 & 25 \\
\hline Elaboração de sinalização informativa & - & - & 08 & & 01 \\
\hline Execução/Reforma de praças e cantinas & - & - & 04 & 04 & - \\
\hline Implementação de rota acessível & - & 01 & 05 & 05 & 01 \\
\hline
\end{tabular}

Em termos urbanísticos, os espaços públicos de convivência, como praças e cantinas foram executados e reformados para atender as condições de desenho universal (Figura 5), como: instalação de placas informativas; sinalização dos acessos e percursos principais com piso tátil (de alerta e direcional); adoção de mobiliário diversificado que possibilita uso abrangente; rebaixamento de balcão de atendimento; e sombreamento dos ambientes. O projeto de rotas acessíveis, corresponde àquelas identificadas no diagnóstico de 2011 e, englobam a sinalização e nivelamento dos passeios das calçadas, faixas elevadas e trajetos de estacionamento. 

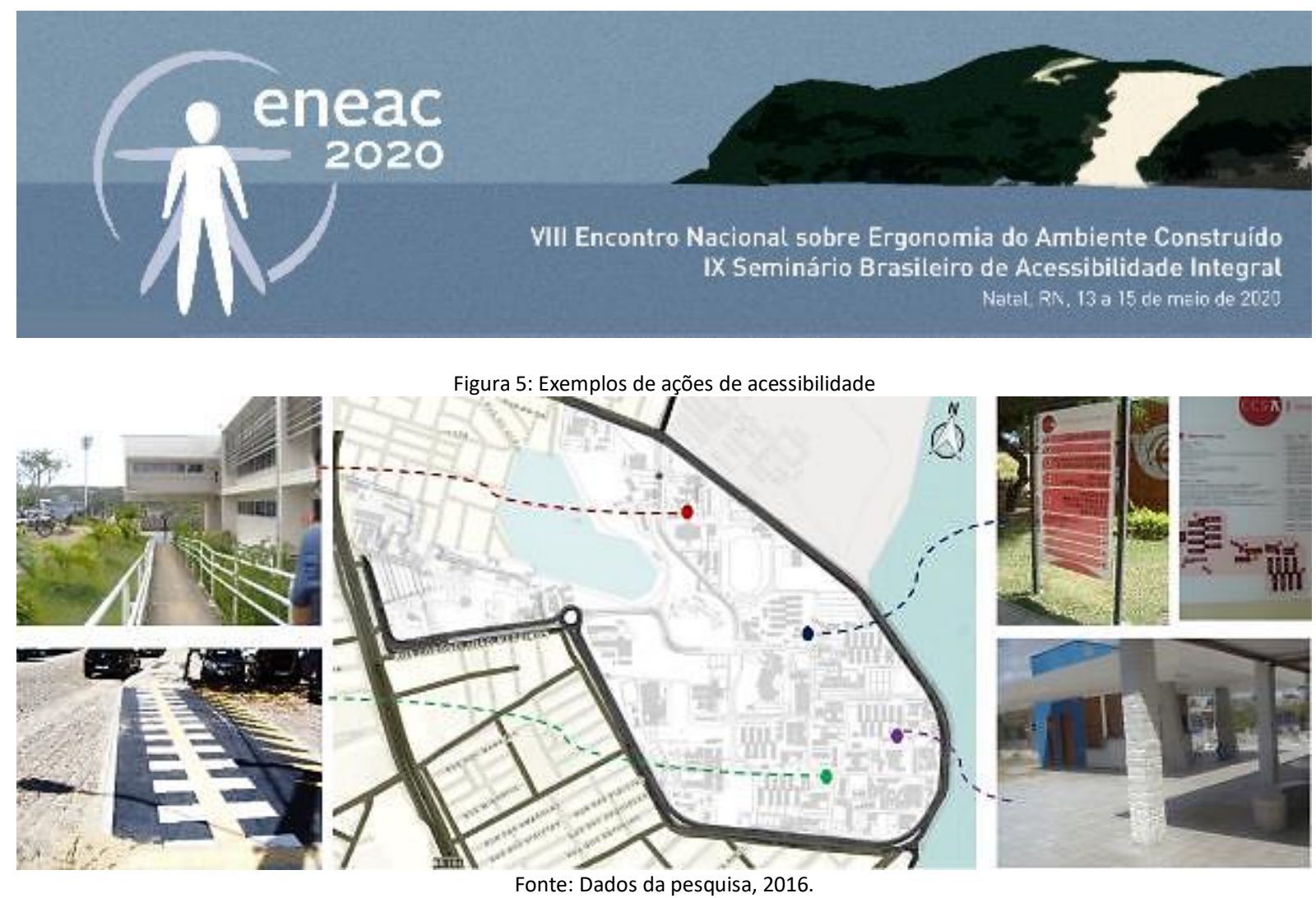

Durante o ano de 2016 as ações aumentaram principalmente por causa da necessidade de atender as mudanças da NBR 9050-2015. Desse modo, o fato do questionário da pesquisa ter sido aplicado no mesmo ano, permitiu que os usuários avaliassem o sistema de mobilidade urbana, enquanto estava sendo modificado, com algumas obras já concluídas e outras, em andamento, o que provocava alguns transtornos comuns ao tipo de intervenção (desvios, poeira, exposição de materiais de construção). Tal situação reforçou a necessidade de analisar a opinião do público que deveria se beneficiar mais dessas ações, apresentada no próximo tópico.

\section{A ACESSIBILIDADE FÍSICA DO CC-UFRN SEGUNDO PCDS E IDOSOS}

A percepção da acessibilidade no Campus Central da UFRN pelas pessoas com deficiência e idosos, corresponde a um quantitativo pequeno considerando o universo de respondentes do questionário original da pesquisa, 4,21\% (51 de 1210). No entanto, o direcionamento dado às suas opiniões é importante para fundamentar a discussão sobre a temática e atualizar o diagnóstico de acessibilidade do campus, visto que o campus passou por modificações constantes nos anos recentes.

Desse grupo de 51 respondentes, a metade se identificou como portadora de algum tipo de deficiência (auditiva, física, cognitiva e visual) e a outra parcela com mais de 59 anos. Dessa maneira, ambos os grupos possuem direitos assegurados pelo Estatuto do Idoso - Lei n.. 10.741/2003 (BRASIL, 2013) e Estatuto da Pessoa com Deficiência - Lei n.o 3.146/2015 (BRASIL, 2015), que garantem a eliminação de barreiras que impeçam a participação social, inclusive as arquitetônicas e urbanísticas.

Na Tabela 3 foram cruzados os dados de ocupação na universidade e faixa etária dos indivíduos de acordo com a deficiência (ou não) indicada. É possível perceber que as respostas são variadas, com relação a ocupação e idade. Mas destacam-se, entre os estudantes de graduação de 18 a 25 anos, um maior número de deficientes físicos e visuais. Dentre os que indicaram possuir nenhuma deficiência, estão os idosos, que em geral, são professores e frequentam o campus por mais tempo. 


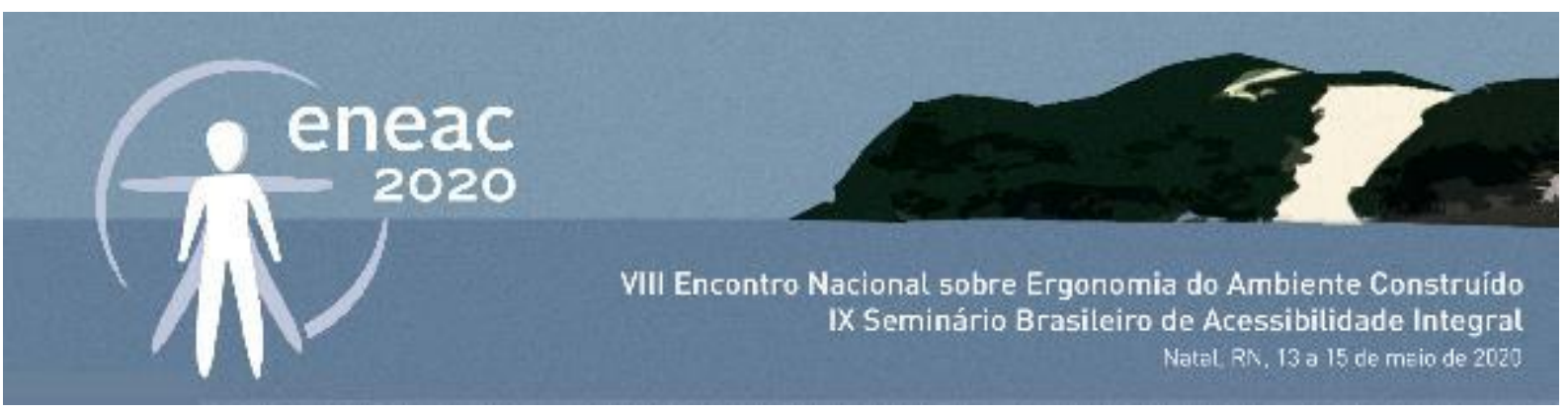

Tabela 3: Tipos de deficiência de acordo com ocupação e idade

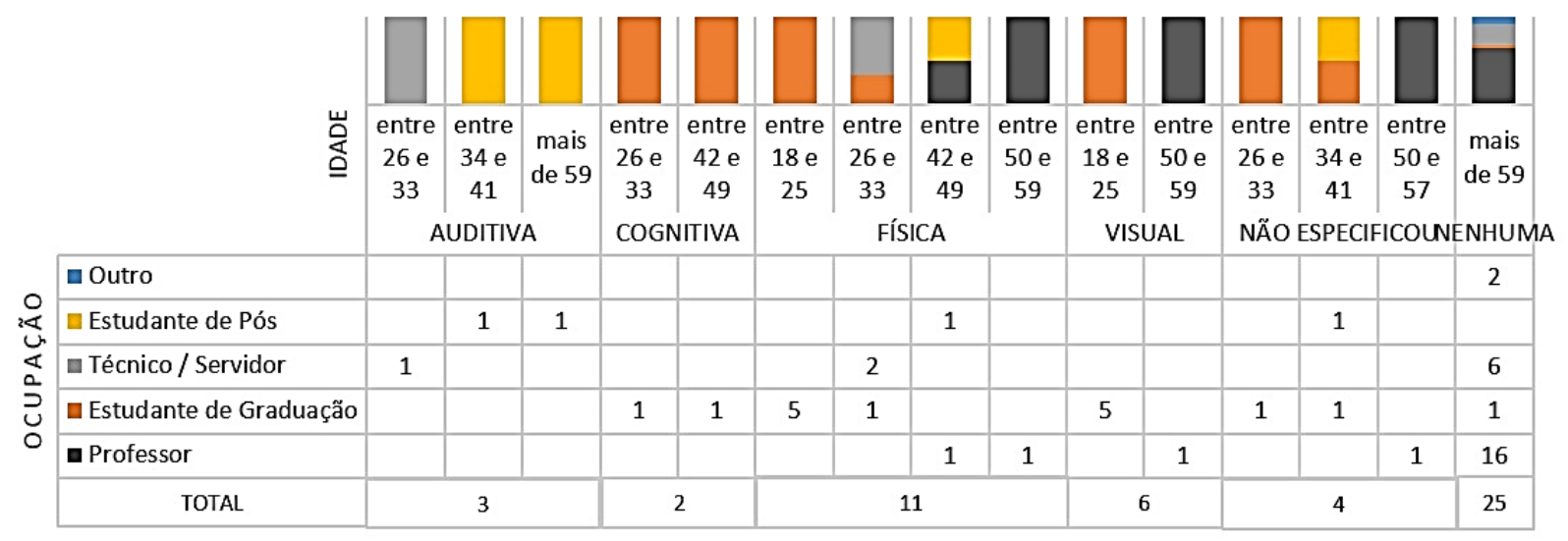

Fonte: Dados da pesquisa, 2016.

Considerando a pergunta disparadora do estudo (A infraestrutura do Campus está adequada para receber pessoas com deficiência?), comparando as respostas do grupo com os da pesquisa original, manteve-se o percentual de 'não sei avaliar' maior do que respostas positivas, permanecendo o valor mais alto para a inadequação da infraestrutura (Tabela 4). Destacam-se as opiniões dos usuários com deficiência auditiva e visual, que não chegaram a considerar a resposta afirmativa.

\begin{tabular}{|c|c|c|c|}
\hline Tipo de deficiência informada & $\begin{array}{c}\text { Não está } \\
\text { adequada }\end{array}$ & $\begin{array}{l}\text { Não sei } \\
\text { avaliar }\end{array}$ & $\begin{array}{l}\text { Sim, está } \\
\text { adequada }\end{array}$ \\
\hline Auditiva & 03 & - & - \\
\hline Cognitiva & 01 & - & 01 \\
\hline Física & 05 & 03 & 03 \\
\hline Visual & 03 & 03 & - \\
\hline Não especificou & 04 & - & - \\
\hline Nenhuma (idoso) & 18 & 04 & 03 \\
\hline Total & 34 & 10 & 07 \\
\hline
\end{tabular}

Para aprofundar as percepções sobre a locomoção no espaço público do CC-UFRN, uma avaliação sobre as perguntas referentes a mobilidade e infraestrutura foi realizada, incluindo aspectos como: modais de transporte; vias; calçadas; acessos; e estacionamentos. Associadas aos dados das respostas, foram incluídas fotografias (registradas na primeira etapa da pesquisa) para retratar algumas situações citadas.

\section{Aspectos de mobilidade e infraestrutura urbana}

Interessado em perceber como essas pessoas se deslocam para o campus e dentro dele, os gráficos da Figura 6 mostram que o modal de transporte que sofre mais variação, nesses dois percursos, é o "a pé", indicando que dentro do campus, é o que teve maior crescimento (um total de 2 para 18). "Carro" e "moto", mantém quantitativos semelhantes, sendo o número de carros alto para os idosos e de motos, baixo entre todos. O "ônibus", decai pela metade (um total de 10 para 5) em se tratando da circulação interna e uso da frota "Circular". 


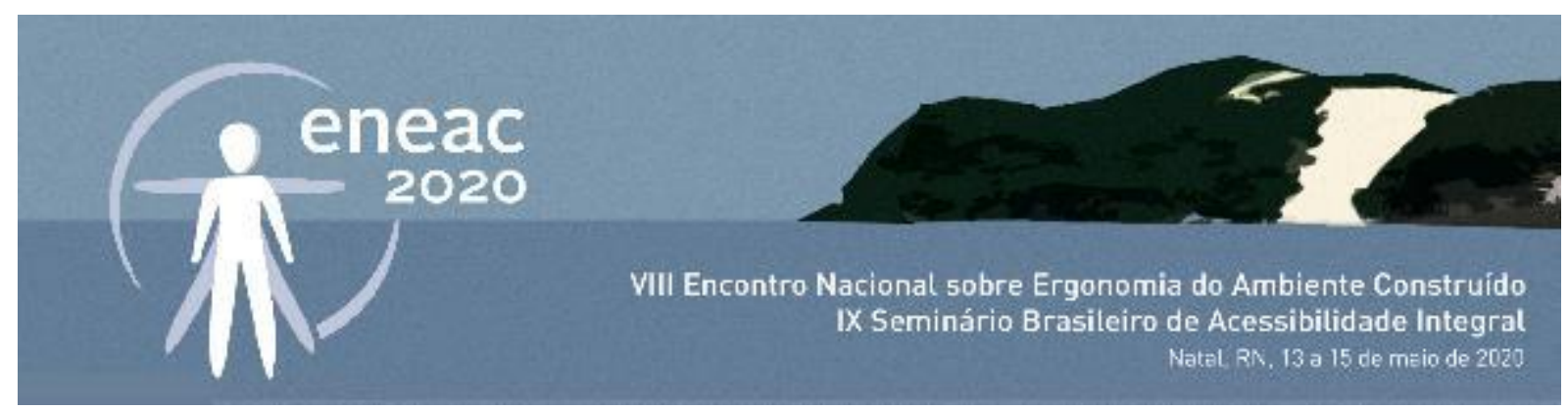

Figura 6: Gráficos dos principais meios de locomoção para chegar e para circular dentro do CC-UFRN
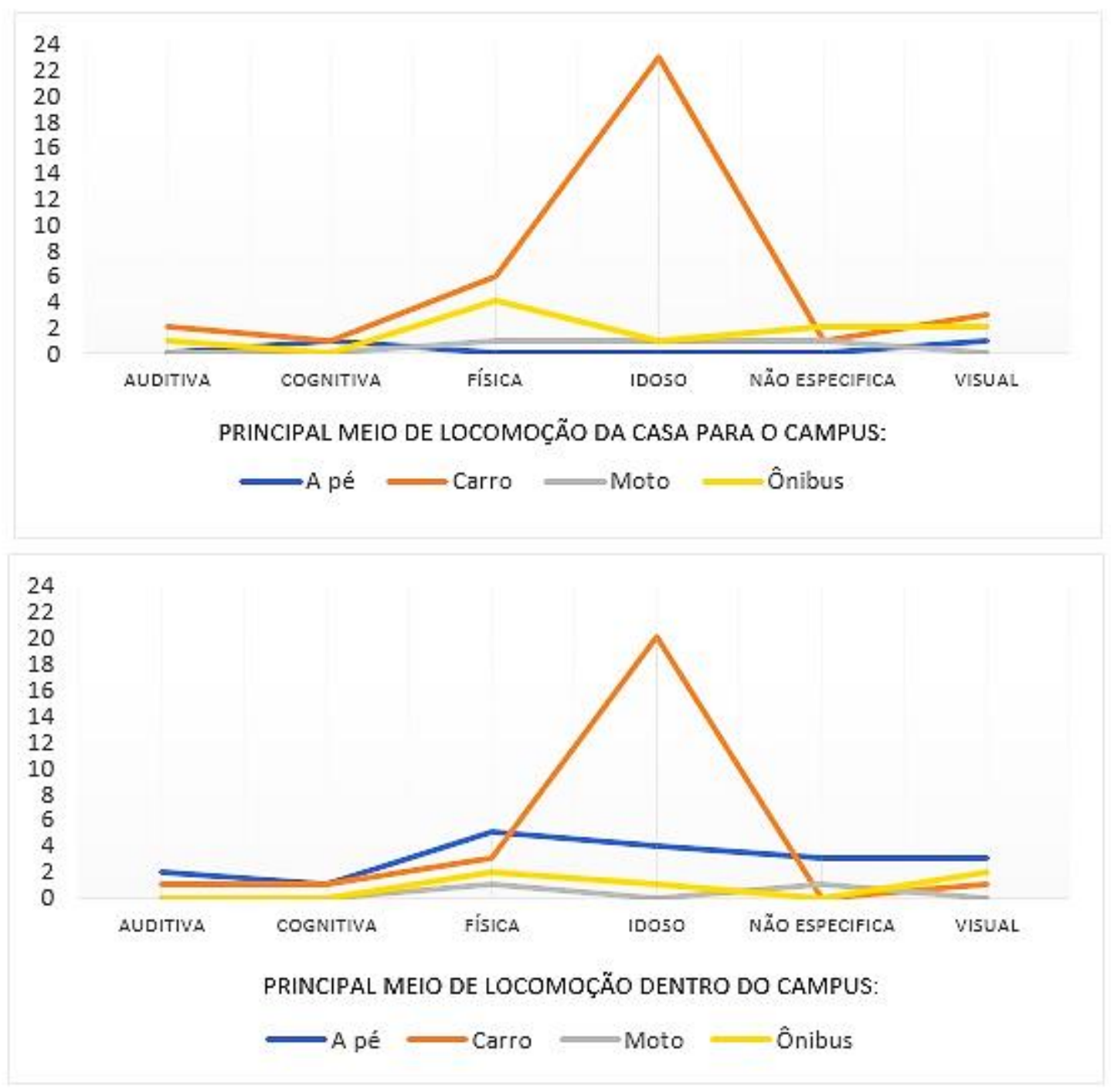

Fonte: Dados da pesquisa, 2016.

Alguns fatores que justificam o baixo uso do "Circular" são: a alta lotação em horários de pico, com muitas pessoas em pé; e apenas um ônibus, do total de oito, possui plataforma elevatória de embarque/desembarque para cadeirantes. Quando questionados sobre a frota, os respondentes que afirmaram utilizar, consideram que a qualidade está entre ruim (34\%), regular (14\%) ou péssima (10\%); tendo a soma das opções negativas o dobro das positivas (21\%) e dos que não souberam avaliar (21\%).

A análise das calçadas, assim como das vias, depende da distância percorrida. Portanto, mesmo que o número de quem ande "a pé" aumente dentre do campus, esses percursos costumam ser mais curtos e referentes ao que os usuários estão habituados. O retrato da subjetividade da resposta e do alto quantitativo de quem usa carros fez com que todos respondentes avaliassem a qualidade das vias, no entanto, sobre as calçadas $4 \%$ assinalou "não sei avaliar". Em termos gerais, as respostas positivas foram maiores para vias do que para as calçadas (Figura 7). 


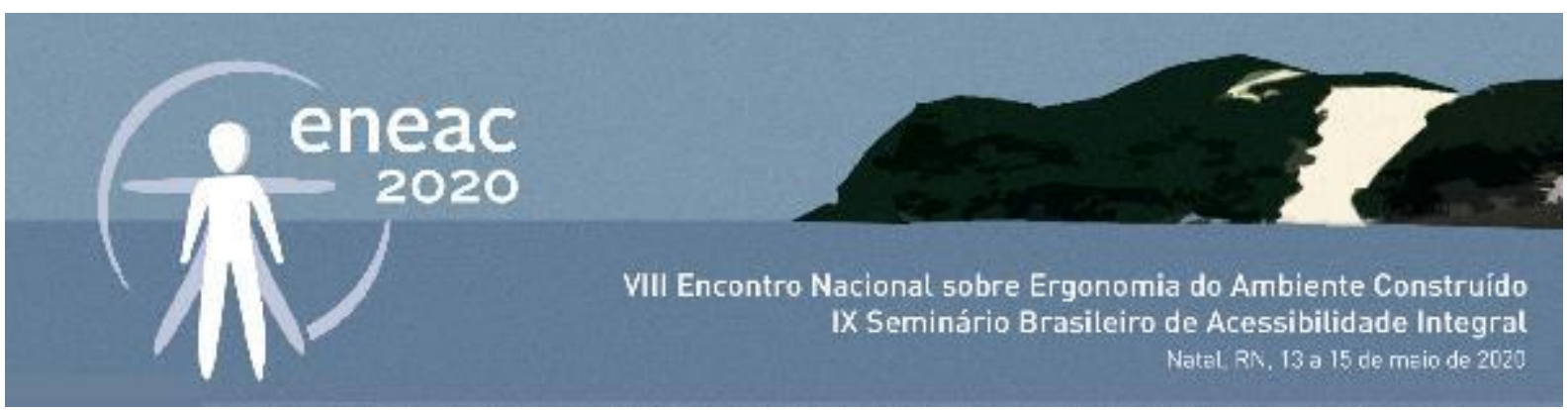

Figura 7: Gráfico da avaliação da qualidade das vias e calçadas

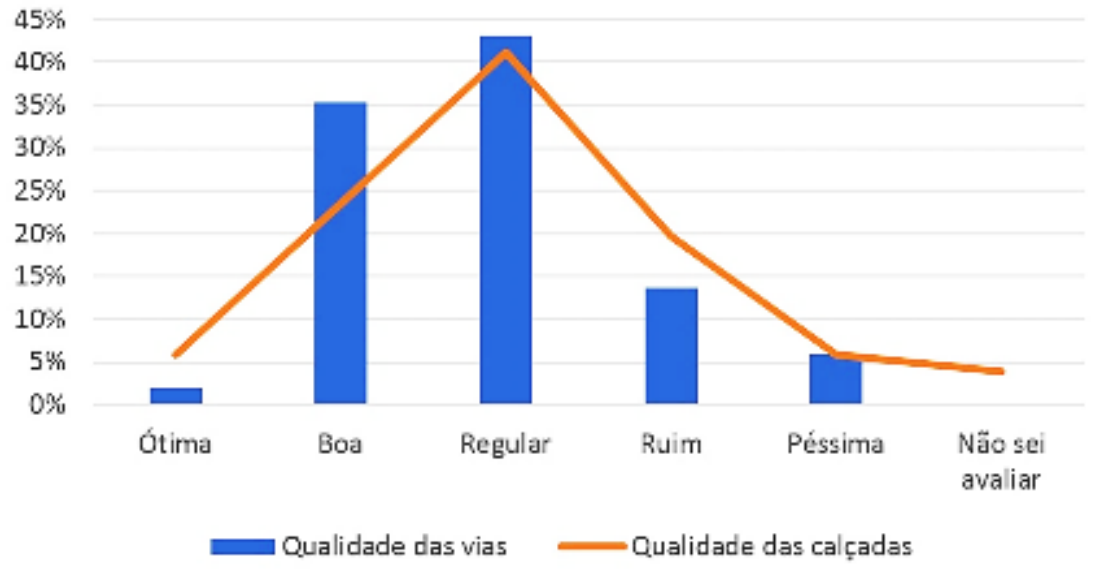

Fonte: Dados da pesquisa, 2016.

Quando questionados sobre o que dificultava a caminhada pelas calçadas (Figura 8), as características mais citadas foram: veículos estacionados de modo irregular (57\%); falta de sombreamento (55\%); e falta de sinalização (55\%), principalmente sonora e tátil. Como na época o campus estava passando por reformas, $25 \%$ destacaram a presença de materiais e entulhos de obras nas calçadas.
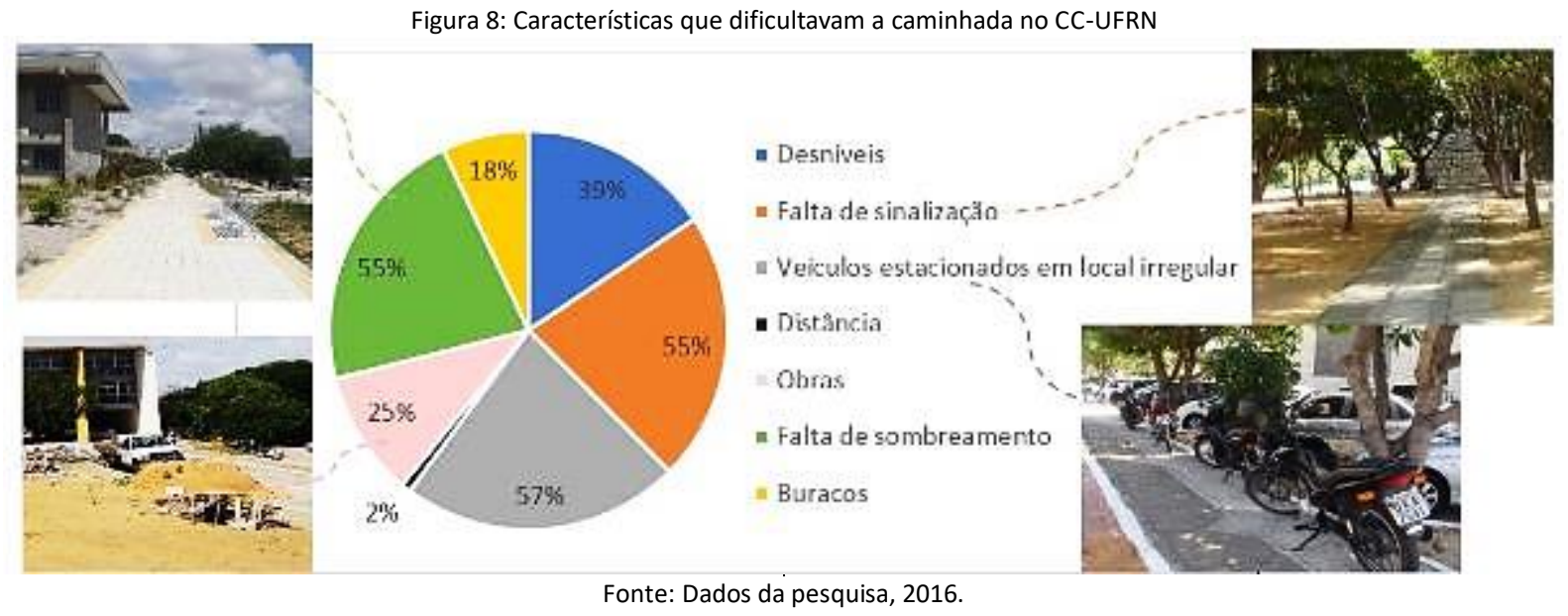

Como os veículos mal estacionadas são os pontos mais prejudiciais durante a locomoção, foi necessário analisar também a qualidade dos estacionamentos. Apesar do maior percentual ser regular (39\%), a soma dos aspectos negativos (36\%) foi o dobro dos positivos (18\%). Além disso, outras perguntas ainda reforçaram os problemas dos estacionamentos, como os respondentes que acreditavam que as vagas são insuficientes (71\%) e que as reservadas para PCDs e idosos não são facilmente identificáveis (59\%).

Pode-se analisar que, as percepções negativas dos estacionamentos são reflexo do modelo rodoviarista a que o campus foi submetido. Pois, mesmo com um sistema viário organizado desde sua fundação e previsão de bolsões de vagas próximas às principais edificações, como priorizou o modal de deslocamento por carro, o CC-UFRN recebe um alto índice de automóveis diariamente que não consegue comportar. As consequências disso são explicitadas diretamente no acesso de algumas 


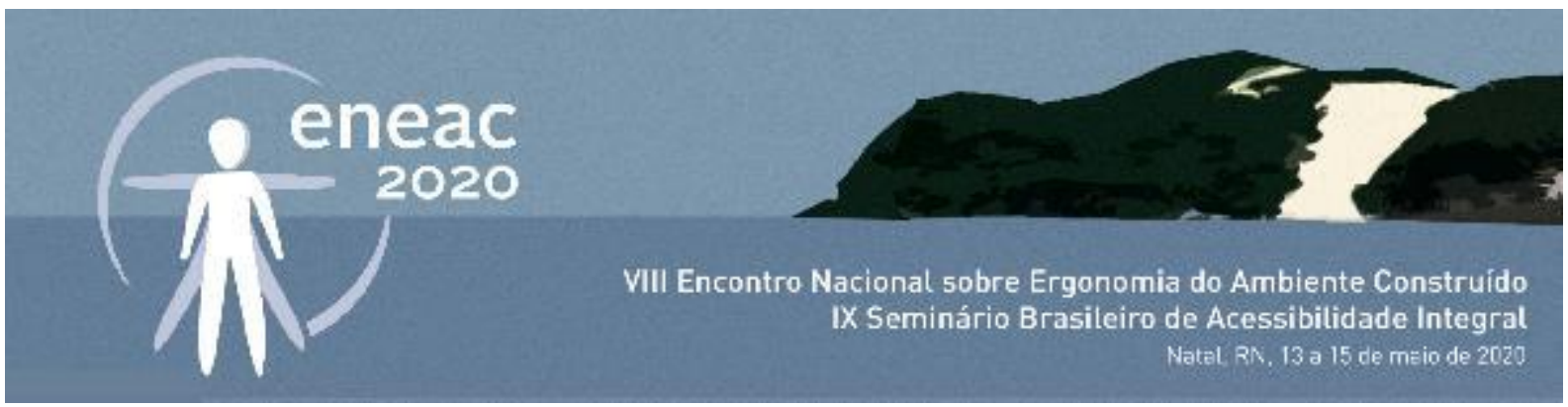

edificações, que contam com: estacionamentos informais em áreas de areia; desgaste na pintura das vagas devido a alta rotatividade de veículos; e presença de vagas reservadas que não se integram às entradas, pois estão desniveladas ou possuem batentes (Figura 9).
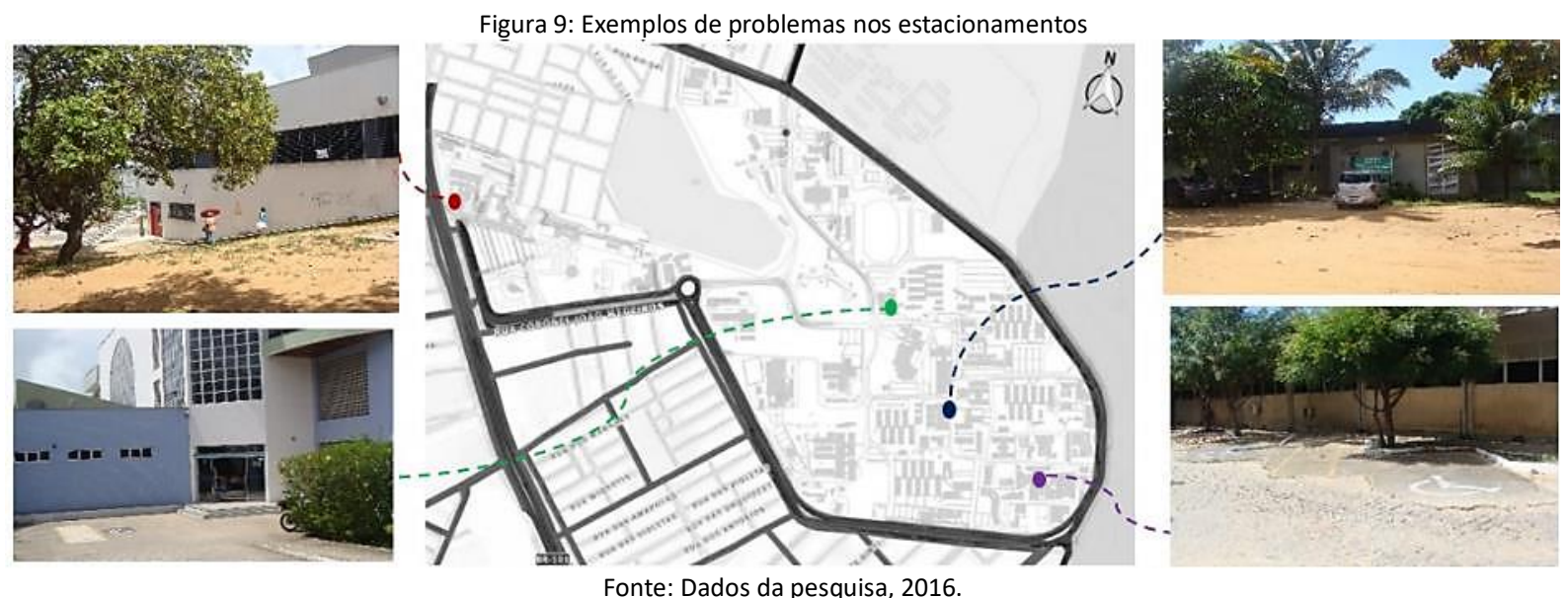

Fonte: Dados da pesquisa, 2016

É importante ressaltar que, além dos aspectos de infraestrutura, algumas questões de hábito também atrapalham a mobilidade no CC-UFRN, prejudicando não apenas as PCDs e idosos, mas qualquer usuário. Dentre as percebidas por esse grupo, estão: comportamento imprudente dos motociclistas; bloqueio dos acessos pelas pessoas (por filas ou ambulantes); e mal-uso das rampas, seja por aqueles que obstruem a passagem sentando nelas ou que descartam lixo (Figura 10).
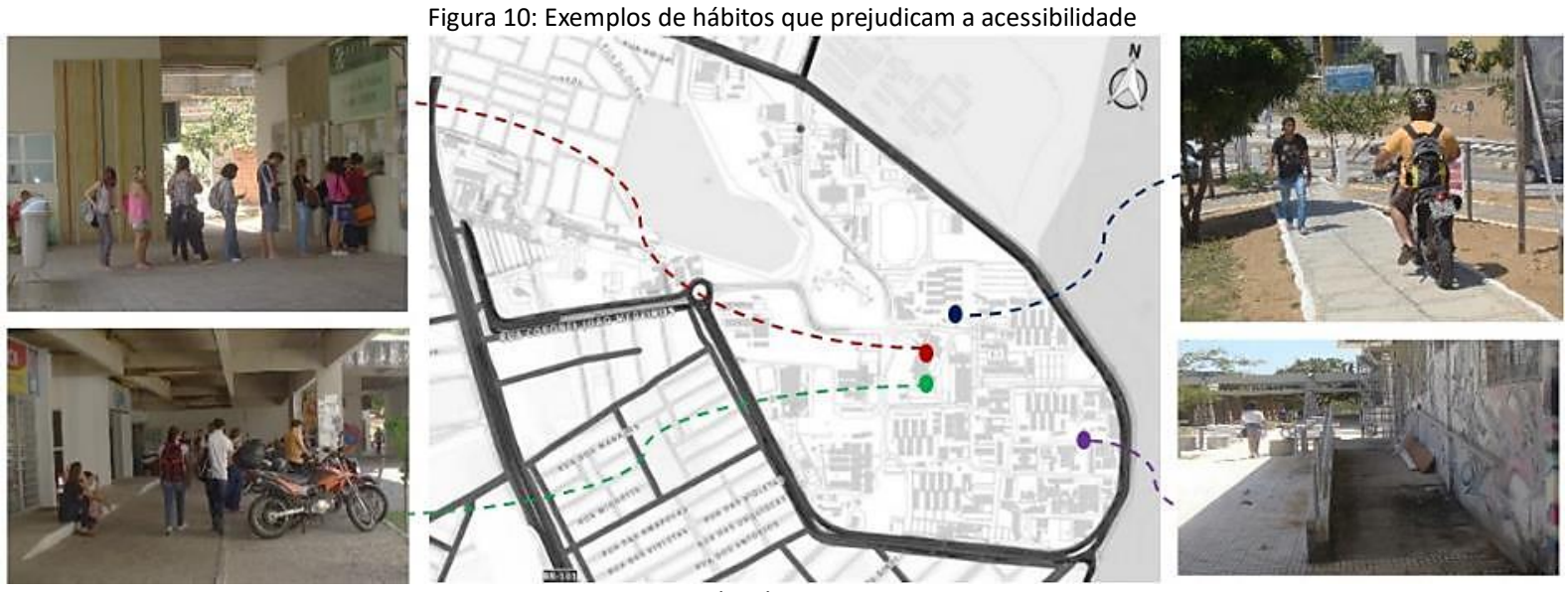

Fonte: Dados da pesquisa, 2016.

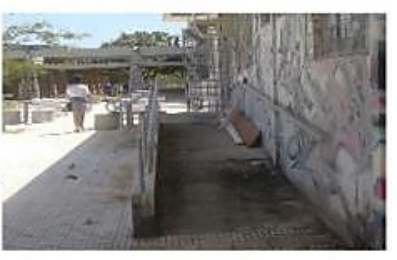

Como balanço geral do tópico, é possível observar que as percepções sobre a mobilidade urbana do CC-UFRN, apesar de partirem das análises subjetivas de um grupo selecionado, refletem questões enfrentadas por todos os que frequentam o campus. Especificamente para as PCDs e idosos, foi possivel ilustrar quais aspectos contribuíram para que $67 \%$ dos respondentes achassem a infraestrutura inadequada para recebê-los (acesso ao "Circular", irregularidades nas calçadas e estacionamentos). Além disso, revelou que as dificuldades a que são expostos não são apenas físicas, mas comunicacional (falta de sinalização e insuficiência de vagas reservadas) e atitudinais. 


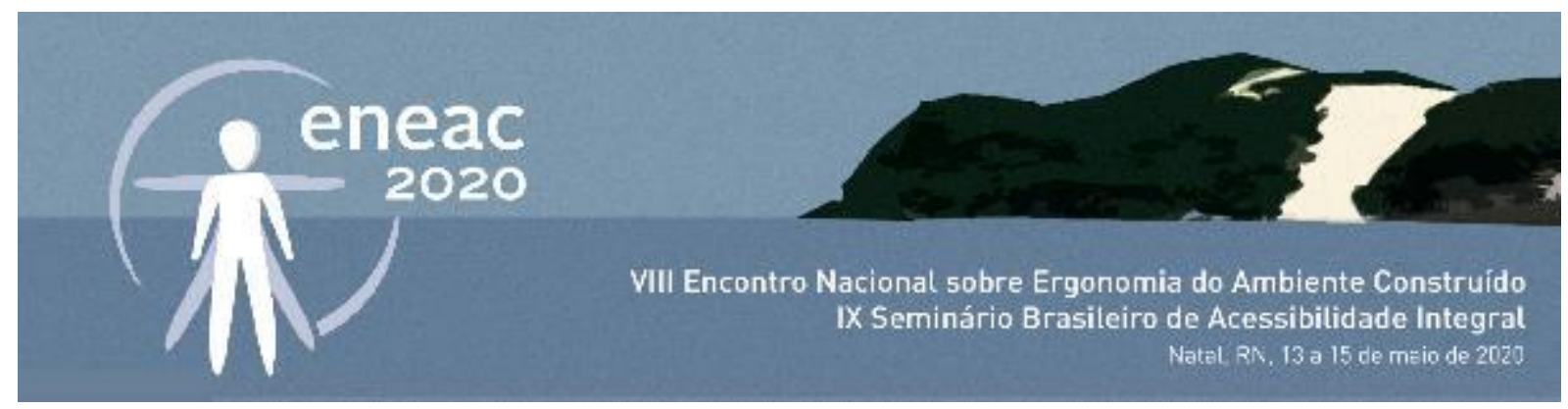

\section{CONSIDERAÇÕES FINAIS}

O presente artigo analisou os resultados de um questionário, aplicado com usuários do campus central da UFRN, como método de avaliação da infraestrutura urbana e sua relação com os ambientes construídos. Para isso, extraiu os dados referentes à percepção das pessoas com mobilidade reduzida (PCDs e idosos) sobre os espaços livres de apoio às edificações (circulações de veículos/pedestres e estacionamentos).

Para dar suporte aos aspectos avaliados nas respostas, foram considerados os documentos divulgados pela Superintendência de Infraestrutura (SIN) sobre as ações de acessibilidade realizadas e em andamento, a fim de entender seus impactos e abrangências. As obras se intensificaram na última década, principalmente após a criação da Comissão de Apoio a Estudantes com Necessidades Educacionais Especiais (2010), publicação do diagnóstico de acessibilidade do campus (UFRN-CAENE, 2011) e guia de orientações (UFRN-CAENE, 2012) para realização de projetos de reformas e rotas acessíveis, adequados a versão atual da NBR 9050 (ABNT, 2015).

Como a pesquisa foi realizada no ano de 2016, registrou-se muitos resultados negativos das questões de acessibilidade. Na época, as opiniões das PCDs e idosos giravam em torno da inadequação da infraestrutura do campus, especialmente no impacto que os problemas de estacionamentos (ou falta de) provocavam nas calçadas e nos acessos as edificações. Além disso, outros aspectos prejudiciais da circulação foram abordados, como: falta de sinalização, decorrente da ausência de um sistema de comunicação diversificado (visual, tátil, auditivo, lumínico), provocando dificuldades de orientação e legibilidade em alguns percursos; má qualidade da frota de ônibus interna; e obstáculos provocados pelo comportamento das pessoas.

O fato da maioria das intervenções de acessibilidade propostas pela SIN já terem sido concluídas e estarem consolidadas em 2019, torna possível afirmar que alguns problemas destacados anteriormente foram reduzidos, especialmente quanto a melhoria da navegabilidade ambiental e qualidade das calçadas inseridas nas rotas acessíveis. No entanto, ainda não garantem a acessibilidade integral, visto que nos lugares que essas rotas não alcançam ou até mesmo os que levam a elas, ainda persistem as dificuldades de mobilidade a pé, principalmente provocadas por outros modais de transporte (veículos mal estacionados) e ausência de sinalização (auditiva e visual).

Dentre as contribuições do trabalho, a metodologia de pesquisa se tornou satisfatória, por englobar no questionário vários aspectos de mobilidade urbana e conseguir captar a opinião dos usuários. Alguns desses dados foram ilustrados com fotografias posicionadas no mapa da UFRN e podem ser cruzados com os que representam a distribuição dos espaços livres e ações de acessibilidade no campus. Além disso, o diagnóstico pode substanciar novos projetos de intervenção que visam maior usabilidade do ambiente por pessoas com deficiência e idosos.

\section{AGRADECIMENTOS}

A autora agradece o apoio do Conselho Nacional de Desenvolvimento Científico e Tecnológico (CNPq) pelo financiamento da pesquisa na época. Bem como da Superintendência da Infraestrutura da Universidade Federal do Rio Grande do Norte, pelos dados e mapas fornecidos. 


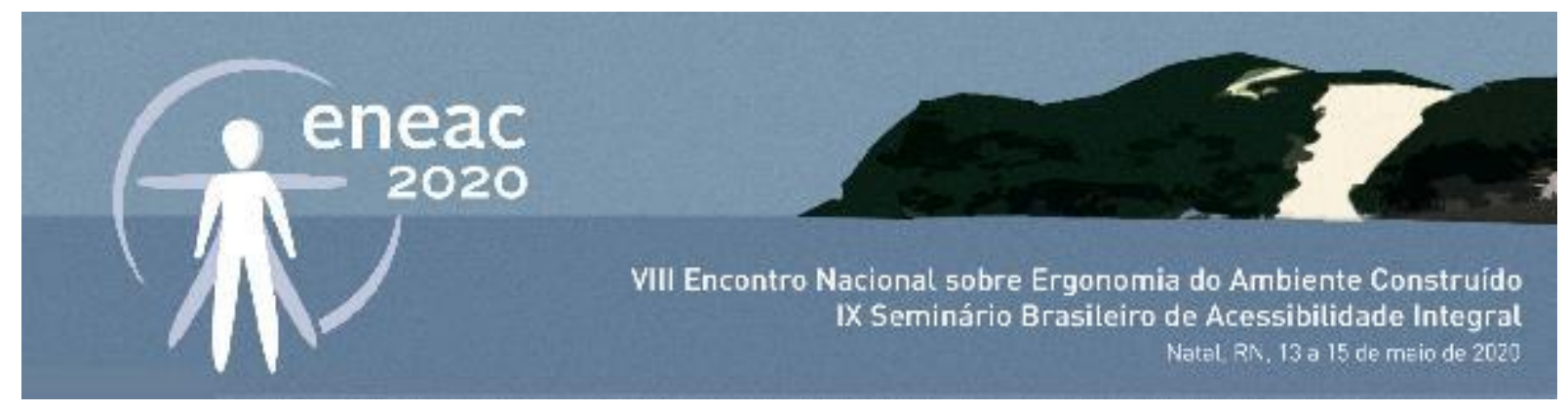

\section{REFERÊNCIAS}

ASSOCIAÇÃO BRASILEIRA DE NORMAS TÉCNICAS. NBR 9050: Acessibilidade a edificações, mobiliário espaços e equipamentos urbanos. 3 ed. (1995 - 1 ed. / 2004 - 2 ed.) Rio de Janeiro: ABNT, 2015.

ATCON, R. P. Rumo à reformulação estrutural da Universidade Brasileira: estudo realizado entre junho e setembro de 1965 para a Diretoria do Ensino Superior do Ministério da Educação e Cultura. Rio de Janeiro: 1966.

BRASIL. Decreto $n^{\circ} 6.096$ de 24 de abril de 2007. Institui o Programa de Apoio a Planos de Reestruturação e Expansão das Universidades Federais - REUNI. Brasília: Ministério da Educação, 2007.

BRASIL. Estatuto do Idoso. 3 ed., 2 reimpr. Brasília: Ministério da Saúde, 2013.

BRASIL. Estatuto da pessoa com deficiência. Brasília: Senado Federal, 2015.

BRASIL. Lei no 13.409, de 28 de dezembro de 2016. Altera a Lei no 12.711, de 29 de agosto de 2012, para dispor sobre a reserva de vagas para pessoas com deficiência nos cursos técnico de nível médio e superior das instituições federais de ensino. Brasília: Ministério da Educação, 2016.

BRASIL. Portaria no 20, de 21 de dezembro de 2017. Dispõe sobre os procedimentos e o padrão decisório dos processos de credenciamento, recredenciamento, autorização, reconhecimento e renovação de reconhecimento de cursos superiores, bem como seus aditamentos, nas modalidades presencial e a distância, das instituições de educação superior do sistema federal de ensino. Brasília: Ministério da Educação, 2017.

ELALI, G. A. Um sistema para avaliação da acessibilidade em edificações do Campus Central da UFRN. In: SEMINÁRIO ACESSIBILIDADE NO COTIDIANO. Anais do ... Rio de Janeiro: 2004, s/p.

GRILO, M. E. G. Análise da ciclovia da Universidade Federal do Rio Grande do Norte, sob a ótica da segurança. Monografia (Graduação). Universidade Federal do Rio Grande do Norte, Centro de Tecnologia, Departamento de Engenharia Civil. Natal, RN, 2016.

LIMA, J. V. F. de. Estudo do desempenho econômico da linha 588 - circular do campus da UFRN. Monografia (Graduação). Universidade Federal do Rio Grande do Norte, Centro de Tecnologia, Departamento de Engenharia Civil. Natal, RN, 2017.

OLIVEIRA, J. A. A universidade e seu território: um estudo sobre as concepções de campus e suas configurações no processo de formação do território da Universidade Federal do Ceará. Dissertação (Mestrado Interinstitucional em Arquitetura e Urbanismo) Universidade de São Paulo/ Universidade Federal do Ceará. São Paulo, 2005.

PREFEITURA MUNICIPAL DO NATAL. Conheça melhor o seu bairro - LAGOA NOVA. Natal: Secretaria Municipal de Meio Ambiente e Urbanismo, 2008.

RODRIGUES, D. S. Sistema de informação para avaliação e monitorização da qualidade de vida em campi universitários. Tese (Doutorado) - Universidade do Minho, Escola de Engenharia, Portugal: 2007.

SARMENTO, B. R. A qualidade ambiental de espaços livres em campi: Um estudo na UFPB e UFRN sob a ótica da Avaliação Pós-Ocupação. Tese (Doutorado). Universidade Federal do Rio Grande do Norte, Centro de Tecnologia, Departamento de Arquitetura. Natal, RN, 2017.

SOUZA, N.C. L. Compreensão dos espaços livres do Campus Central da UFRN pela comunidade universitária. In: Anais do eCICT - XXVIII Congresso De Iniciação Científica E Tecnológica, Natal: UFRN, 2017.

SUPERINTENDÊNCIA DA INFRAESTRUTURA. Ações de acessibilidade física 2014-15-16-17. Natal: SIN, 2019.

UNIVERSIDADE FEDERAL DO RIO GRANDE DO NORTE - COMISSÃO DE APOIO A ESTUDANTES COM NECESSIDADES ESPECIAIS. Acessibilidade na UFRN: guia de orientações básicas. Natal: UFRN-CAENE, 2012.

UNIVERSIDADE FEDERAL DO RIO GRANDE DO NORTE - COMISSÃO DE APOIO A ESTUDANTES COM NECESSIDADES ESPECIAIS. Diagnóstico de acessibilidade Campus Central da UFRN e campi avançados: CERES Currais Novos, CERES Caicó e FACISA Santa Cruz. Natal: UFRN-CAENE, 2011.

UNIVERSIDADE FEDERAL DO RIO GRANDE DO NORTE. Plano Diretor do Campus Universitário Central. Anexo da Resolução no 028/2007. Natal: CONSAD, 2007. 